\title{
Solvent Extraction of Iron(III) with Tri Methyl Amine from Mineral Acid Solutions
}

\author{
A.V.L.N.S.H. HARIHARAN*, K. MANASA and J.V.S.K.V. KALYANI \\ Department of Chemistry, GIT, GITAM University, Visakhapatnam - 530 045, India \\ ahharan@gmail.com
}

Received 28 May 2014 / Accepted 29 June 2014

\begin{abstract}
Solvent extraction of iron(III) was carried out with $2.5 \times 10^{-2} \mathrm{M}$ of Tri methylamine in chloroform from hydrochloric, sulphuric and nitric acid solutions. After extraction iron(III) was stripped from the organic phase with $1.0 \mathrm{M} \mathrm{H}_{2} \mathrm{SO}_{4}$ and was determined using AAS method. The extractions were quantitative with hydrochloric and nitric acid systems and 95\% from sulphuric acid solutions employed in the study. Based on the results obtained, estimation of iron in natural and industrial samples has been attempted.
\end{abstract}

Keywords: Extraction, Iron(III), Tri methylamine, Mineral acid, Chloroform, Industrial samples

\section{Introduction}

Iron deficiency anemia is one of the world's most common nutritional deficiency diseases. At low levels iron is an essential element in the diet, whereas at higher concentrations it is toxic ${ }^{1}$. Because of the different biological roles of iron in humans, animals, plants, and oceans, the need for analysis of iron in environmental and biomedical materials have been increased considerable attention. Solvent extraction of Iron(III) from aqueous hydrochloric ${ }^{2-4}$ and sulphuric ${ }^{5}$ and mineral acid ${ }^{6,7}$ solutions by various amines has been studied.

There are no studies reported in literature on the extraction of Iron(III) with tri methylamine (TMA). Therefore this paper presents an account on the extraction of Iron(III) with TMA in presence of mineral acids. The method of extraction has been extended for the separation of Iron(III) in different samples.

\section{Experimental}

A stock solution $(0.25 \mathrm{M})$ of Iron(III) was prepared by dissolving appropriate amount of ammonium Iron(III) sulfate (E.Merck) in $500 \mathrm{~mL}$ double distilled water. The solution was standardized volumetrically ${ }^{8}$ with potassium dichromate using diphenyl amine as the indicator. A diluted solution of Iron(III) of appropriate concentration was prepared from the stock solution as per the requirement. A solution of $2.5 \times 10^{-2} \mathrm{M}$ TMA in chloroform is used for throughout the extraction. 


\section{Procedure for iron (III) extraction}

An aliquot $(20 \mathrm{~mL})$ of a solution containing Iron(III) was taken and was added with appropriate concentration of mineral acid. The resulting solution was transferred to a reparatory funnel and $20 \mathrm{~mL}$ of $2.5 \times 10^{-2} \mathrm{M}$ of TMA was added to it. The solution was vigorously shaken for 5-10 minutes. The two phases were allowed to settle and separate. Iron(III) from the organic phase was stripped with $10 \mathrm{~mL}$ of $1 \mathrm{M} \mathrm{H}_{2} \mathrm{SO}_{4}$. The concentration of Iron(III) in both the phases was determined by AAS method.

\section{Results and Discussion}

\section{Variation of acidity}

Iron(III) was extracted from mineral acid solutions ( $\mathrm{HCl}, \mathrm{H}_{2} \mathrm{SO}_{4}$ and $\mathrm{HNO}_{3}$ ) with $2.5 \times 10^{-2} \mathrm{M}$ TMA in and the results are presented in Figure 1. The variation of distribution ratio as a function of aqueous phase concentration of the acid $\left(\mathrm{HCl} \mathrm{H}_{2} \mathrm{SO}_{4}\right.$ and $\left.\mathrm{HClO}_{4}\right)$. From hydrochloric and nitric acid solutions, the distribution ratio $(\mathrm{Kd})$ increased with increasing the concentration of the acid up to $9.0 \mathrm{M}$ (Maximum extraction of $99.31 \%$ \& $98.57 \%$ respectively) and remained constant up to $11.0 \mathrm{M}$ acidity. The extractions are nearly quantitative. On the other hand the extraction from sulphuric acid solutions (by TMA in chloroform as a function of acidity), the distribution ratio $(\mathrm{Kd})$ gradually increased with increasing the concentration of the acid up to $10.0 \mathrm{M}$ (maximum at 94.07\%) followed decrease in extraction is observed.

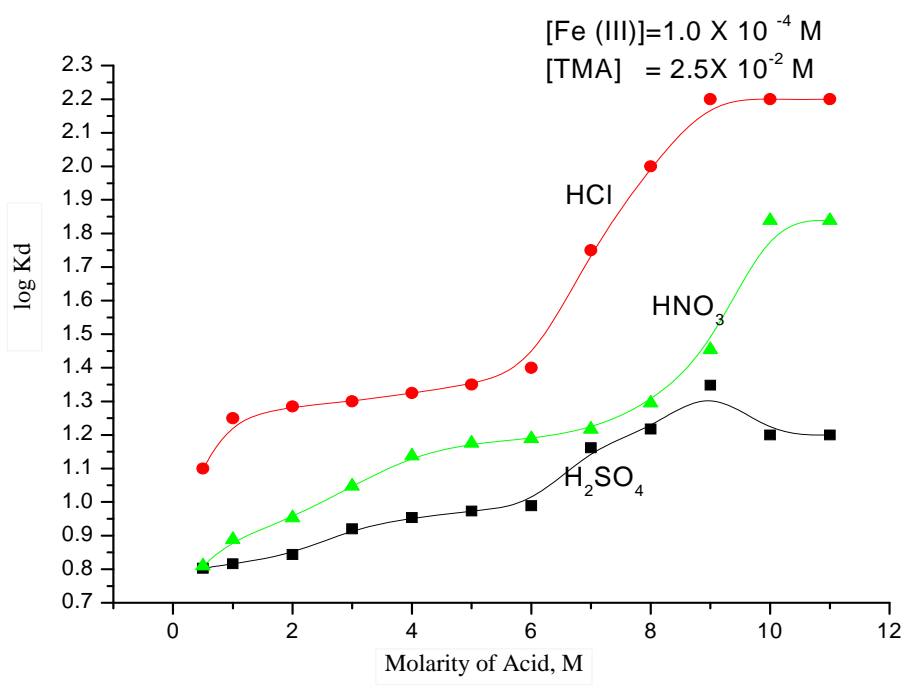

Figure 1. Variation of Acidity

\section{Composition of the extracted species}

The extraction isotherm method ${ }^{9}$ and distribution ratio method ${ }^{10}$ were employed to determine the composition of the extracted species. In the extraction isotherm method the limiting ratio of the metal to TMA was found unity with all the acid systems (Figure 2). With all other factors being kept constant, Iron(III) was extracted with $20 \mathrm{~mL}$ of TMA with concentration, varying from $1.0 \times 10^{-2} \mathrm{M}$ to $4.5 \times 10^{-2} \mathrm{M}$. The log-log plots of Kd vs. TMA from various acid solutions gave straight lines of with unit slope expect sulphuric acid media (solvation number is two). Figure 3 corresponds to plot from hydrochloric acid media. 


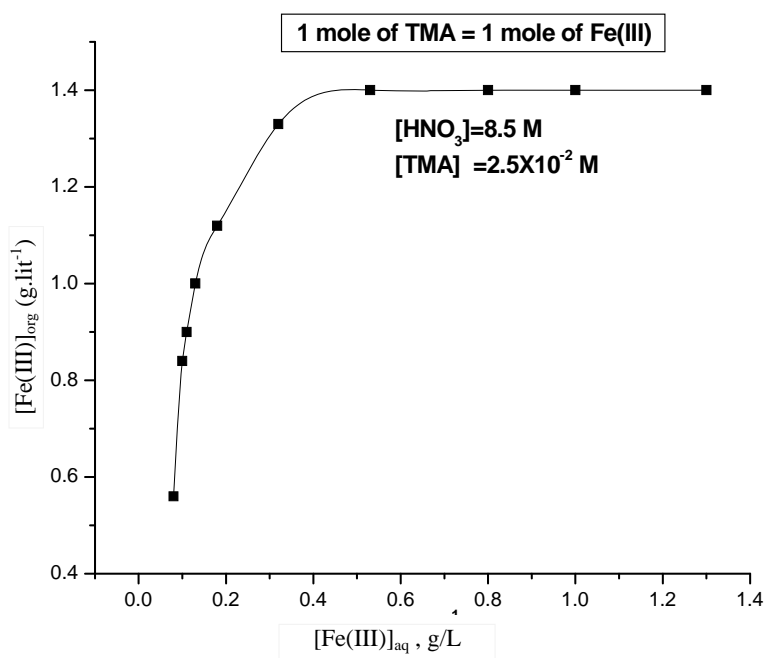

Figure 2. Extraction isotherm

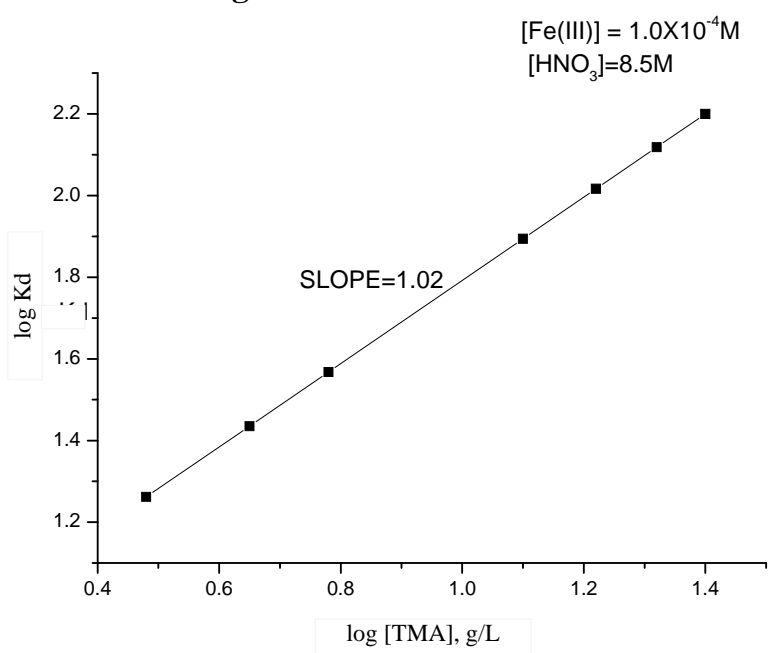

Figure 3. Extraction variation

\section{Effect of various stripping agents}

After extraction, Iron(III) was stripped with $20 \mathrm{~mL}$ reagents of various concentrations (0.1-1.0 M) of $\mathrm{HCl}, \mathrm{HNO}_{3}, \mathrm{CH}_{3} \mathrm{COOH}$ and $\mathrm{H}_{2} \mathrm{SO}_{4}$ solutions. It was observed that $1.0 \mathrm{M} \mathrm{H}_{2} \mathrm{SO}_{4}$ alone is a good stripping agent. However in no case the acid strips out all the Iron(III) in a single extraction. $99.7 \%$ Iron(III) could be recovered from organic phase by making contact three times with equal volumes of $1.0 \mathrm{M} \mathrm{H}_{2} \mathrm{SO}_{4}$.

\section{Extraction mechanism}

From hydrochloric $\left(\right.$ Smulek $\left.^{11}\right)$ and nitric acid solutions:

$\mathrm{TMAHCl}+\mathrm{Fe}^{3+}+4 \mathrm{Cl}^{-} \rightleftharpoons\left[\mathrm{TMAH}+\mathrm{FeCl}_{4}^{-}\right]_{\text {org }}+\mathrm{Cl}^{-}$

$\mathrm{TMAHNO}_{3}+\mathrm{Fe}^{3+}+4 \mathrm{NO}_{3}^{-} \rightleftharpoons\left[\mathrm{TMAH}+\mathrm{Fe}\left(\mathrm{NO}_{3}\right)^{4-}\right]_{\mathrm{org}}+\mathrm{NO}_{3}^{-}$

From sulphuric acid solutions: 
$2(\mathrm{TMA})_{2} \mathrm{SO}_{4}+2 \mathrm{Fe}^{3+}+2 \mathrm{SO}_{4}{ }^{2-}+2 \mathrm{H}_{2} \mathrm{O}_{(\mathrm{aq})} \rightleftharpoons\left[(\mathrm{TMAH})_{2} \mathrm{SO}_{4} \cdot \mathrm{FeOH}\left(\mathrm{SO}_{4}\right)_{2}\right]_{2 \text { org }}+2 \mathrm{H}^{+}$

\section{Analysis of iron in natural and industrial waste water samples}

The validity of the method of extraction for recovery of iron has been tested in different samples. The samples were weighed accurately (0.5-1.0 g) and finely powdered in a mortar. An exact weight of the powdered sample was dissolved in an aliquot of aquaregia.

The solution was evaporated and extracted with dilute hydrochloric acid solution. The mixture was shaken well for about $15 \mathrm{~min}$. Then the mixture was diluted by $0.01 \mathrm{M} \mathrm{HCl}$ solution to the mark and then filtered by Whatmann filter paper No. 40. The first portion of filtrate was discarded. The clear solution obtained was made up to $100 \mathrm{~mL}$ and used as stock solution. $20 \mathrm{~mL}$ of this iron solution was shaken for five minutes with an equal volume of $2.5 \times 10^{-2} \mathrm{M}$ of TMA.

An aliquot $(20 \mathrm{~mL})$ of the filtered effluent sample was heated to $1 / 5^{\text {th }}$ of the initial volume. It was then made up to $100 \mathrm{~mL}$. $20 \mathrm{~mL}$ of this solution was extracted with an equal volume of $2.5 \times 10^{-2} \mathrm{M}$ TMA in chloroform. After separation of two phases, Iron(III) (present in both natural as well as industrial sample) from the organic phase was stripped with $10 \mathrm{~mL}$ of $1.0 \mathrm{M}$ sulphuric acid and was determined by AAS as described earlier. The results obtained in these studies were compared by extracting iron from synthetic samples with \% composition $\mathrm{Fe}=1.0-3.0 \mathrm{ppm}, \mathrm{pH}=2.5$ and $\mathrm{NO}_{3}{ }^{-}=1.0 \mathrm{M}$ (Tables $1 \& 2$ ).

Table 1. Estimation of iron in food and vegetable samples

\begin{tabular}{cccc}
\hline Sample & Iron present, \% & Iron found by extraction, \% & \% Recovery \\
\hline Green gram & 4.05 & 3.92 & 96.8 \\
Raw rice & 30.0 & 29.51 & 98.37 \\
Spinach & 20.0 & 19.06 & 95.45 \\
Soya beans & 20.0 & 19.82 & 99.10 \\
\hline
\end{tabular}

Table 2. Analysis of Iron(III) in industrial (plating) waste water

\begin{tabular}{ccccc}
\hline S.No. & Date & Effluent sample & Extn. method, ppm & AAS method \\
\hline 1 & $01-02-2014$ & 1 & 2.25 & 2.17 \\
2 & $15-02-2014$ & 2 & 2.34 & 1.99 \\
3 & $01-03-2014$ & 3 & 1.91 & 1.80 \\
4 & $15-03-2014$ & 4 & 2.24 & 2.37 \\
5 & $01-04-2014$ & 5 & 2.10 & 2.09 \\
6 & $15-04-2014$ & 6 & 2.08 & 2.01 \\
7 & $01-05-2014$ & 7 & 1.52 & 1.42 \\
8 & Effluent & 1.(Before & ---- & 2.6 \\
& sample : & recycling) & & 0.35 \\
9 & & 2.(After & ---- & \\
& & recycling)
\end{tabular}

\section{Conclusion}

It was observed that within a amount of time, determination of Iron(III) content can be performed effectively. The current method has practical utility as Iron(III) can be separated from electroplating effluents that contain chromium, cadmium and zinc (under the experimental conditions). It can be concluded from these studies that the proposed method and AAS method were in good agreement with each other. 


\section{Acknowledgement}

Thanks are due to Dr. V. Muralidhara Rao, Retd. Professor, School of Chemistry, Andhra University, Visakhapatnam for his valuable suggestions. Thanks are also due to Principal, GIT and Management of GITAM University for providing necessary facilities

\section{References}

1. Ghadamali B, Mansour A C and Zeinab B, Eurasian J Anal Chem., 2009, 4(3), 285-293.

2. Sahu K K and Das R.P, Metllrgy Met Trans B, 2000, 31(6), 1169-1174; 10.1007/s11663-000-0003-5

3. $\quad$ Lee M S and Lee K J, Hydrometallurgy, 2005, 80(3), 163-169;

DOI:10.1016/j.hydromet.2005.06.010

4. $\quad$ Staszak K, Clerpiszewski R and Prochaska K, Polish J Chem Tech., 2011, 13(1), 1-5.

5. $\quad$ Alguacil F J and Amer S, Polyhedron, 1986, 5(11), 1755-1161; DOI:10.1016/S0277-5387(00)84853-6

6. Astrid G I and Biseska T, Croatica Chemica Acta., 2003, 76(4), 323-328.

7. Hariharan A V L N S H, Sudhakar Ch and Venkateswara Rao B, Asian J Res Chem., 2012, 5(2), 245-247.

8. Vogel A I, A Text book of quantitative Inorganic Analysis, $3^{\text {rd }}$ Edition, Longman, London, 1962.

9. ColemanC F, Brown K B, Moore J G and Allen K A, Proc $2^{\text {nd }}$ Intl Conf., Peaceful uses of Atomic Energy, Geneva, 1958, C.10, 510.

10. Hesford E.and Mckay H A C, Faraday Soc Trans., 1958, 54, 573-586; DOI:10.1039/TF9585400573

11. Smulek W and Siekierski S, J Inorg Nucl Chem., 1962, 24(12), 1651-1666; DOI:10.1016/0022-1902(62)80020-7 